
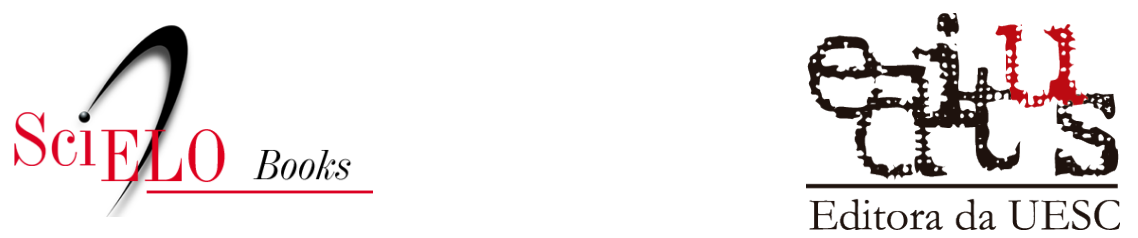

\title{
3 Da colonialidade à emancipação: uma história possível
}

\author{
Raíssa Félix
}

\section{SciELO Books / SciELO Livros / SciELO Libros}

FÉLIX, R. Da colonialidade à emancipação: uma história possível. In: Volta miúda: quilombo, memória e emancipação [online]. Ilhéus, BA: Editus, 2020, pp. 49-66. Transfluência series. ISBN: 978-65-86213-14-0. https://doi.org/10.7476/9786586213317.0004.

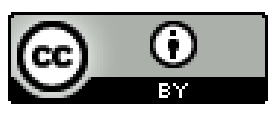

All the contents of this work, except where otherwise noted, is licensed under a Creative Commons Attribution 4.0 International license.

Todo o conteúdo deste trabalho, exceto quando houver ressalva, é publicado sob a licença Creative Commons Atribição 4.0.

Todo el contenido de esta obra, excepto donde se indique lo contrario, está bajo licencia de la licencia Creative Commons Reconocimento 4.0. 


\section{Da colonialidade à emancipação: uma história possível}

A história do território político soberano a que hoje se denomina República Federativa do Brasil inicia no contexto da política de expansão mercantilista europeia datada de meados do século XVI. O aprimoramento da tecnologia de navegação oceânica possibilitou o contato e relacionamento entre diferentes e distantes sociedades, e da mesma forma abriu caminhos para a sua conquista e subsunção a novas estruturas de poder. Alguns teóricos, a exemplo de Norberto Bobbio, Nicola Matteucci e Gianfranco Pasquino (1998) e Isabel de Castro Henriques (2014), segmentam o fenômeno da colonização ao destacar as características mais evidentes em determinados períodos. Importa trazer à baila que, se inicialmente a conquista de territórios para fins econômicos respondia à necessidade de as Nações se afirmarem diante das outras potências, por meio da conquista e garantia de fontes para exploração de riquezas materiais ou humana, por meio da escravidão -, o caráter político-ideológico da colonização se fortaleceu a ponto 
tal que a política internacional passou a ser remodelada pela capacidade de controle e ingerência política, econômica e cultural sobre outros povos.

Se, numa linguagem simplista, considerarmos que 0 desenvolvimento industrial adicionou à equação da acumulação de riqueza bruta e poder a necessidade de existência de mercado consumidor para as riquezas beneficiadas, a coIonização, sistematicamente implementada para fins de controle para exploração de riquezas, personifica-se no projeto político do colonialismo. O termo distancia a compreensão do colono como participante do processo de povoamento de novos territórios, aduzindo que a descontinuidade territorial e cultural apurada atende a fins mais amplos do que a mera exploração de riquezas. "O Colonialismo transforma-se num método de organização da produção baseado na exploração de uma força de trabalho privada de direitos políticos e sociais no âmbito do Estado colonial" (BOBBIO; MATTEUCCl; PASQUINO, 1998, p. 183), o que se destaca é o caráter deliberado da política colonialista para a dominação e repressão dos povos colonizados, protraindo os efeitos deste controle por meio da subalternização de grupos igualmente privados dos seus direitos, ainda que formalmente "descolonizados".

Quijano chama atenção ao fato de que com os movimentos de independência dos territórios conquistados e mesmo depois de eliminado o controle político direto dos colonizadores em relação às suas colônias - como no caso brasileiro, em 1822, quando fora declarada a independência em relação ao Reino Português -, "la relación entre la cultura europea, también 'occidental', y las otras sigue sendo una relación de dominación colonial" (QUIJANO, 1992, p. 12). A 
poética da sua escrita não afasta a nocividade do processo, que ultrapassa a dominação cultural, atuando diretamente no imaginário das sociedades, de forma a tornar-se, em certa medida, componente das individualidades. A descontinuidade identitária alcança a própria humanidade dos corpos, por reprimir sistematicamente as suas crenças, ideias, símbolos e conhecimentos.

Fazendo referência às práticas do colonialismo, mas num contexto pós-colonial, o imperialismo é enunciativo da hegemonia de um Estado em detrimento de outro, sobre o qual aquele exerce o controle econômico, subsumindo-o, inclusive, ideologicamente. Neste contexto é que se configura a transmutação das formas de dominação. Se outrora a dicotomia colonizadores e colonizados estabelecia o lugar social e jurídico do indivíduo, a proclamação de "independência" descaracterizou o status de colônia, implicando a remodelação das nomenclaturas de poder sem que houvessem mudanças estruturais. Neste âmbito, a subalternização de grupos atende de forma sistemática e estratégica aos interesses imperialistas e a divisão étnico-racial assume o papel de instrumento para depreciação da história e memória dos povos que deram origem à nação. Enquanto os brancos, outrora colonizadores, mantêm a sua soberania, a categoria dos colonizados é substituída pela dos negros - a cor da escravidão -, e mestiços, frutos da mistura inconcebível ${ }^{5}$ entre os grupos sucedidos.

É na deturpação da representação social conforme os interesses da cultura lato sensu hegemônica imposta que a lógica imperialista legitima a relação de dominação,
5. "Os mestiços eram de tal forma depreciados, e animalizados, que os naturalistas chegaram a temer que fossem estéreis, denominandoos 'mulatos', em associação às mulas". (SILVA, 2011, p. 162) 
[...] na medida em que as relações sociais que se estavam configurando eram relações de dominação, tais identidades foram associadas às hierarquias, lugares e papéis sociais correspondentes, como constitutivas delas, e, consequentemente, ao padrão de dominação que se impunha. Em outras palavras, raça e identidade racial foram estabelecidas como instrumentos de classificação social básica da população. (QUIJANO, 2005, p. 107).

O sociólogo peruano argumenta que a relação de dominação direta, política, social e cultural dos europeus introduziu uma estrutura colonial de discriminações. O raciocínio que se constrói é quanto à subsunção da lógica local para consolidação da identidade e estabilidade da nação brasileira, mas forjada sob os paradigmas que favorecem e são concebidos à perspectiva do colonizador. Se outrora os negros tinham sido descritos como decrépitos de espírito e disformes no corpo e, portanto, desinteressantes para a formação da sociedade brasileira - o que garantia a preponderância do europeu -, em dado percurso histórico se fez politicamente necessário que uma identidade própria fosse criada para consolidação da nação independente, e abriu-se concessão à miscigenação (SILVA, 2011). Destaca-se que, mesmo neste último cenário, permanece imaculada a hegemonia colonizadora, uma vez que, se na teoria fora criado um laço entre brancos e negros, a prática reservou-lhes a exclusão social. Complementando este raciocínio, Silvane Silva (2005) rememora Kabengele Munanga, o qual percebe que do fenômeno da miscigenação - enquanto fenômeno biológico - resulta um fato social, psicológico, econômico, político-ideológico, corroborando a ideia de que a política racial se estabeleceu no Brasil para atender aos interesses da elite branca/colonizadora. 
Considerando que "a representação do social se relaciona com a memória e a experiência, além da reflexividade, enquanto enunciado da modernidade, e tem implicação nas formas de reconhecimento nos planos social, cultural e político" (SCHERER-WARREN, 2010, p. 22), a subalternidade assimilada aos negros pode-se dizer fruto de um processo histórico de violência real, materializado na escravidão, e simbólica - aparentemente silente e indolor, mas altamente deletéria (BOURDIEU, 1989, p. 10) -, que culminou no alijamento da sua cidadania.

Decerto, esse processo de depreciação social, identitária e histórica voltada à marginalização da população negra se sustentou graças à manutenção institucionalizada da política colonialista, que fundamenta o Estado brasileiro. Abdias Nascimento alerta:

Seja dito desde o início os afro-brasileiros formam uma etnia encurralada pelo cerco de um sistema de pressões que vão desde o preconceito e a discriminação veladas, até as agressões culturais e/ou psicológicas, assim como se radicalizam em violências abertas de sentido econômico e de cunho policial ou institucional. [...] - está condenado ao desaparecimento ditado pela sociedade dominante, pois assim está determinado pela lógica da política racial vigente no país. (NASCIMENTO, 2019, p. 186).

A hegemonia das potências imperialistas prescinde da fragmentação nacional e hierarquização das relações de poder, fomentadas pela subalternização de determinadas categorias sociais e o seu afastamento aos direitos e garantias de desenvolvimento, pois, ao passo em que o negro é desconsiderado em sua humanidade, o mecanismo ideológico 
escuda esse próprio grupo hegemônico da responsabilidade social para com o futuro desses ex-escravizados e seus descendentes.

Neste contexto se elucida o porquê da representação social pejorativa atribuída à população negra, de forma animalizada, construída de forma apartada da dimensão humana da existência intelectual, sensitiva, cultural e emocional, haja vista que, um dos paradoxos da situação colonial (BALANDIER, 2014, p. 46-47) instaurada é a preponderância da influência sociológica, ainda que por um grupo numericamente inferior. $O$ que realmente importa/define $\mathrm{n} /$ esta relação e seus desdobramentos é a manutenção do lugar do dominador e do dominado.

É consentâneo pensar que, tendo sido as relações étnico-raciais estabelecidas no Brasil sob o critério da colonialidade, o processo de exclusão social e usurpação da cidadania tem na educação - sem o prejuízo de outros espaços - terreno fértil à contínua subalternização da população negra e seus descendentes. E isto se afirma por dois vieses: em primeiro plano, destaca-se a apatia constitucional voltada à inserção da população negra na escola, e em segundo plano a desvalorização dos saberes, métodos e instrumentos formativos deslocados do modelo eurocêntrico, mas inerentes à cultura negra e de riqueza historicamente ignorada.

Boaventura de Sousa Santos (2009) denomina conhecimento o que aqui se refere, de forma institucionalizada, como educação. Trata-se de linguagem política responsável por traduzir a práxis social, de forma inteligível, trazendo-a ao plano da existência. Esta compreensão denota que a concepção moderna do conhecimento é dotada de 
intencionalidade nociva à coexistência de saberes, partindo-se do pressuposto de que a imposição de uma forma de saber é uma manifestação de controle político. Desta maneira, a colonização dos saberes não implica apenas a subalternização de outros saberes ou o impedimento de que grupos não hegemônicos os apreendam, mas implica também a alienação do fazer histórico e cultural de uma dada comunidade, levando-a a ignorar os percursos formativos que ultrapassem a normalidade concebida, ainda que lhes sejam natos.

Neste ponto, educação e direito se intersectam. Se por um lado, a ciência moderna monopoliza o certo e o errado, o verdadeiro e o falso, o direito moderno estatui o legal e o ilegal, fazendo erigir a legitimidade unidirecional do Estado tal como se postulasse o direito das gentes. Por intermédio de tais instrumentos se consolidou a hegemonia eurocentrada, ignorando-se as vidas e vivências concebidas além dos seus conceitos. Santos (2009, p. 26) elucida que, "em cada um dos dois grandes domínios - a ciência e o direito - as divisões levadas a cabo pelas linhas globais são abissais no sentido em que eliminam definitivamente quaisquer realidades que se encontrem do outro lado da linha", universo de experiências desperdiçadas e invisibilizadas, tal qual os seus autores.

A racialização das relações sociais e o alijamento da população negra do processo educacional formativo - ainda que em termos eurocentrados - instauram a orfandade cultural, uma vez que suas práticas e saberes não são sequer reconhecidos, e mutilam as possibilidades de participação desta parcela da população no processo/modelo político instaurado. Se, por um lado, a ampliação do acesso 
à educação é crucial à elementar dignidade, a representatividade dos conteúdos e práticas pedagógicas é igualmente sensível e necessária à democratização de saberes. Nesse sentido é que se perquire o reconhecimento do negro enquanto cidadão, a partir do desenvolvimento de um direito à educação hábil a percebê-lo em sua humanidade, ratificando que, como assevera Santos (2009, p. 32), a injustiça social está intimamente ligada à injustiça cognitiva global.

Considerando-se, pois, que a evolução da política educacional dialogue com o seu afastamento da lógica coIonialista, o reconhecimento das relações étnico-raciais se instala como necessário à realização daquele princípio, assim como vai de encontro às hierarquizações sociais concebidas para a manutenção das relações de poder advindas da colonização. Nesse ínterim é que se torna pertinente o questionamento sobre desde quando as portas das escolas brasileiras estão de fato abertas à população pluriétnica e pluricultural que conforma esta sociedade.

Tendo a dignidade da pessoa humana por fundamento (BRASIL, 1988, Art. $1^{\circ}$ ), enquanto Estado Democrático de Direito, a República pós-ditadura nasce com o objetivo de erradicar a pobreza, reduzir as desigualdades sociais e regionais e promover o bem de todos sem prejuízo de origem, raça, sexo, cor, idade e quaisquer outras formas de discriminação (BRASIL, 1988, Art. $3^{\circ}$ ). Conquanto termos similares já tivessem sido cunhados noutros textos constitucionais, a diferenciação está na busca da realização desses objetivos em função de um patamar de dignidade humana, com vistas ao alcance de uma igualdade substantiva, material. Em consonância, se outrora houvera disposições esparsas, 
a Constituição analítica estatui explicitamente a educação como direito social. Sobre a imperatividade dos direitos sociais, econômicos e culturais, Flávia Piovesan (2014, p. 173) concorda que a "ideia da não acionabilidade dos direitos sociais é meramente ideológica e não científica", sendo, irrefutavelmente, exigíveis, o que também reforça a pauta dos movimentos sociais.

Abramovich e Courtis (1997, p. 337) reiteram, sobre a previsão dos direitos sociais, que “Lo que calificará la existência de um derecho social como derecho pleno no es simplemente la conducta cumplida por el Estado, sino la existencia de algún poder jurídico para actuar del titular del derecho em caso de incumplimiento de la obligación debida". Neste ponto de vista, a abertura de possibilidade para a transformação da práxis representa um avanço em contraponto à participação popular na realização da sua liberdade, até então formalmente inaudível pela figura Estatal.

O artigo 205 da Constituição de 1988 localiza a educação como direito de todos e dever do Estado e da família, a ser promovida e incentivada com a colaboração da sociedade, com os objetivos de desenvolver a pessoa, prepará-la para o exercício da cidadania e qualificá-la para o trabalho. Do emblemático artigo $5^{\circ}$ advém o imperativo que se desdobra na inderrogável tarefa de repensar a política educacional brasileira: “XLI - a lei punirá qualquer discriminação atentatória dos direitos e liberdades fundamentais; XLII - a prática do racismo constitui crime inafiançável e imprescritível, sujeito à pena de reclusão, nos termos da lei" (BRASIL, 1988, Art. $5^{\circ}$ ). Ora, se o repúdio ao terrorismo e ao racismo é princípio da República, a descolonização das práticas 
educacionais é conduta imprescindível a fim de que o passivo histórico-social não torne o Estado em verdugo à própria instituição.

Estas perspectivas favorecem a interpretação culturalista e identitária dos movimentos sociais, que, em termos de estudos pós-coloniais, argumentam ser possível a liberdade, com a desconstrução das formações discursivas e da construção de novas subjetividades dos sujeitos historicamente oprimidos e discriminados. A superação das formações discursivas é possível na deflagração da "outra face" oculta e essencial da modernidade implantada, produto do desenvolvimento e notabilidade eurocêntrica: o mundo periférico colonial (SCHERER-WARREN, 2010, p. 20-21).

Compreendendo-se, então, que a hierarquização das relações sociais adveio da imposição de uma cultura colonialista; que a manifestação sociocultural dos povos que, de fato, promoveram o povoamento e ergueram o território Brasil foi violentamente reprimida; que, por consequência, o modelo educacional estabelecido foi silente quanto à inserção desta população, por séculos alijada da alfabetização e dos mecanismos necessários à construção da sua cidadania de forma a perpetuar as condições de dominação e privilégio da elite econômica, quaisquer princípios que decorram deste sistema afrontam o estatuído princípio da dignidade humana.

Ao discorrer sobre princípios para a investigação e análise de práticas dialógicas entre estudos pós-coloniais e movimentos sociais latino-americanos, Scherer-Warren (2010, p. 21-26) faz conclusões que facilitam a compreensão da correlação aqui estabelecida quanto à análise do 
desenvolvimento da política educacional do ponto de vista pós-colonial, com vistas à sua consecução no âmbito das relações étnico-raciais. Se, como já referenciado, o processo de representação social se relaciona com a memória e experiência, o reconhecimento social, cultural, político e epistêmico desta população subalternizada deve ser promovido com a ocupação desses lugares por atores negros e pela pluralidade étnico-cultural formadora do Brasil, em contraponto à marginalização da cultura, saberes e práticas formativas ou educacionais em relação aos centros hegemônicos de poder.

Em relatório intitulado "Faces da Desigualdade no Brasil: um olhar sobre os que ficam para trás", coordenado pela economista Tereza Campello (2017), o acesso aos espaços de formação e formulação de conhecimento por atores negros - que correspondem a mais da metade da população brasileira - é quantificado, a partir de dados do Instituto Brasileiro de Geografia e Estatística (IBGE). Nos dados analisados entre os anos de 2002 e 2015, verificou-se o aumento de $117 \%$ na taxa de jovens negros de 15 a 17 anos, cursando o Ensino Médio, enquanto a presença de jovens negros na universidade cresceu $268 \%$ no mesmo período. A publicação argumenta que tal êxito se deu em função da "ampliação do acesso na busca da universalização que permitiu a inclusão massiva nas políticas sociais, aliada ao aumento da renda do trabalho" (CAMPELLO, 2017, p. 47), com inovações legislativas significativas concernentes à temática das relações étnico-raciais.

O período assinalado foi de grande efervescência legislativa no tocante às relações étnico-raciais e teve como marco a Declaração e Programa de Ação de Durban adotados 
na III Conferência Mundial de Combate ao Racismo, Discriminação Racial, Xenofobia e Intolerância Correlata, realizada em Durban, África do Sul, em 2001. No ano seguinte, o Programa Nacional de Ações Afirmativas foi criado por meio do Decreto n. ${ }^{\circ}$ 4.228, de 13 de maio de 2002 (BRASIL, 2002), pautando reivindicações há muito ecoadas pelos movimentos sociais. Posteriormente, a Lei de Diretrizes e Bases da Educação - Lei n. ${ }^{\circ} 9.394 / 96$ (BRASIL, 1996) - passou por alterações significativas, promovidas pela Lei n. ${ }^{\circ}$ 10.639/03 (BRASIL, 2003) que, acrescendo-lhe os artigos 26-A, 79-A (posteriormente vetado), e 79-B, incluiu a temática "História e Cultura Afro-Brasileira" no currículo oficial da educação básica, e incluiu no calendário escolar a data 20 de novembro como "Dia Nacional da Consciência Negra". Estes diplomas viriam a ser novamente alterados, por meio da Lei n. ${ }^{\circ} 11.645 / 08$ (BRASIL, 2008), para incluir também como temática obrigatória a ser trabalhada em toda a educação básica, nas redes pública e privada de ensino, a história e a cultura dos povos indígenas do Brasil.

Ao regulamentar as alterações promovidas, o ConseIho Nacional de Educação, por meio da Resolução $n .^{\circ}{ }^{1}$, de 17 de junho de 2004, institui as Diretrizes Curriculares Nacionais para a Educação das Relações Étnico-Raciais, tendo por meta promover a educação de cidadãos atuantes e conscientes no seio da sociedade multicultural e pluriétnica (BRASIL, 2013) - e o faz em tom coercitivo às unidades de ensino, haja vista que a sua implementação passaria a ser considerada para avaliação das condições de funcionamento dos estabelecimentos. Ratificando os progressos alcançados no âmbito da política educacional, o Brasil ainda aprova nos anos de 2009 e 2010, respectivamente, o Plano Nacional de 
Promoção da Igualdade Racial (Decreto n. ${ }^{\circ} 6.872$ / 09 - BRA$\mathrm{SIL}, 2009$ ) e o Estatuto da Igualdade Racial (Lei n. ${ }^{\circ} 12.288$, de 20 de julho de 2010 - BRASIL, 2010).

No tocante às taxas de analfabetismo das pessoas de 15 anos ou mais de idade, a Pesquisa Nacional por Amostra de Domicílios (PNAD) promovida pelo IBGE constatou, no ano de 2002, que 7,5 \% da população brasileira declarada como branca não era alfabetizada, em contrapartida, esta porcentagem era significativamente superior em relação aos pretos (16,7\%) e pardos (17,3\%) (BRASIL, 2003). No ano de 2015, percebe-se a redução geral da taxa de analfabetismo, mas, ainda assim, o grupo de pretos ou pardos se encontra em desvantagem gritante, visto que a taxa de analfabetismo para esse grupo $(10,6 \%)$ é mais que duas vezes superior à taxa da população branca (4,9\%) não alfabetizada. Nesse mesmo ano, pretos ou pardos correspondiam a 53,9\% da população brasileira (BRASIL, 2016). Já no ano de 2019, a Síntese de Indicadores Sociais do PNAD aponta a permanência da desigualdade: a taxa de analfabetismo entre as pessoas brancas é de 3,9\% e entre os pretos e pardos é de $9,1 \%$ (IBGE, 2O2Ob). Ainda conforme o último levantamento, no tocante à situação de domicílio, $5,1 \%$ da população urbana e $17,5 \%$ da população rural são analfabetas.

Depreende-se, por meio dos dados analisados, que as políticas públicas implementadas impactaram de maneira positiva, porém incipiente, no tocante à inserção da população negra no sistema formal de ensino e na sua alfabetização - ainda, os dados demonstram que há uma superposição de opressões em relação às comunidades quilombolas que, além da negritude, carregam o caractere ruralista, em 
relação ao qual a discrepância do acesso à educação é ainda mais alarmante. Importa destacar que a descolonização do ambiente educacional implica a ocupação dos espaços por atores negros, assim como a reformulação epistêmica, a partir das suas experiências e vivências, capaz de reconhecer valores culturais historicamente negados, pois, como asseverado por Petronilha Beatriz Gonçalves e Silva no parecer relativo às Diretrizes Curriculares Nacionais para a Educação das Relações Étnico-Raciais e para o Ensino de História e Cultura Afro-Brasileira e Africana:

Reconhecimento implica justiça e iguais direitos sociais, civis, culturais e econômicos, bem como valorização da diversidade daquilo que distingue os negros dos outros grupos que compõem a população brasileira. E isto requer mudança nos discursos, raciocínios, lógicas, gestos, posturas, modo de tratar as pessoas negras. Requer também que se conheça a sua história e cultura apresentadas, explicadas, buscando-se especificamente desconstruir o mito da democracia racial na sociedade brasileira; mito este que difunde a crença de que, se os negros não atingem os mesmos patamares que os não negros, é por falta de competência ou de interesse, desconsiderando as desigualdades seculares que a estrutura social hierárquica cria com prejuízos para os negros. Reconhecimento requer a adoção de políticas educacionais e de estratégias pedagógicas de valorização da diversidade, a fim de superar a desigualdade étnico-racial presente na educação escolar brasileira, nos diferentes níveis de ensino. (BRASIL, 2013, p. 134, grifos meus).

Se por um lado, a interpretação dos direitos humanos prolatados em sede constitucional possa influenciar a universalização do ensino, a descolonização epistêmica implica 
assimilá-la numa concepção da igualdade material. Ou seja, compreendendo os sujeitos subalternizados como cidadãos de direito e, mediante as suas experiências e saberes, aplicar-se-ia os direitos humanos a partir de um universalismo capaz de considerar as diferenças. Esta reinterpretação realoca o próprio sentido do direito à educação, que, outrora concebido num status de concessão, passa a ser incorporado como prerrogativa inerente ao sujeito, percebido em sua inteireza social, cultural e histórica. O qual é, ao mesmo tempo, hábil a prolatá-lo, ainda que em termos diversos ao modelo imposto.

De grande relevância é a percepção crítica das relações étnico-raciais que Ramón Grosfoguel faz no prisma da depreciação da população e cultura negras pela imposição de uma lógica imperialista com raízes no colonialismo.

\footnotetext{
O facto de alguém se situar socialmente no lado oprimido das relações de poder não significa automaticamente que pense epistemicamente a partir de um lugar epistémico subalterno. Justamente, o êxito do sistema-mundo colonial/moderno reside em levar os sujeitos socialmente situados no lado oprimido da diferença colonial a pensar epistemicamente como aqueles que se encontram em posições dominantes. As perspectivas epistémicas subalternas são uma forma de conhecimento que, vindo de baixo, origina uma perspectiva crítica do conhecimento hegemónico nas relações de poder envolvidas. (GROSFOGUEL, 2008, p. 46, grifos meus).
}

A retomada das perspectivas ignoradas é tarefa primária para o questionamento de uma sociedade que se estabeleceu pelos valores do homem masculino, heterossexual, 
branco, patriarcal, cristão, militar, capitalista e para o amadurecimento de infindos questionamentos sobre os sujeitos, lugares, verdades e valores consolidados. Abre-se um novo e longo caminho de percepções e reformulações teóricas e práticas, que revelam a tríade basilar da representação social - posição, localização e memória - contingencialmente. A pós-colonialidade imprime um novo paradigma à coexistência de memórias, implicando a reflexão sobre onde e por que tais e tais sujeitos ocupam e habitam seus respectivos lugares sociais.

Quijano (2009, p. 74) adverte que o "eurocentrismo não é exclusivamente, portanto, a perspectiva cognitiva dos europeus, ou apenas dos dominantes do capitalismo mundial, mas também do conjunto dos educados sob a sua hegemonia". Conceber uma mudança epistêmica e, portanto, política, com vistas a uma emancipação cognitiva dos sujeitos de direito, implica perceber os negros e sua pluralidade cultural - enquanto representativos das populações subalternizadas -, como fontes de conhecimento e detentores dos espaços de aprendizagem e produção de saberes. Portanto, pensar um direito à educação no Brasil implica questionar o acesso das populações negras à escola, assim como à sua liberdade de manifestação epistêmico-cultural para além dos modelos impostos.

A colonialidade de fato alterou a conformação da sociedade brasileira, afetou a priorização política e permitiu o continuísmo de condutas arbitrárias e contrárias aos ideais da liberdade e dignidade humanas. O caminho para a transformação desta realidade implica a abertura de caminhos às culturas ignoradas, dar voz para a produção do 
conhecimento que se afaste dos modelos e paradigmas eurocêntricos. Esta crítica é feita pelo professor e historiador Francisco Antônio Nunes Neto, ao tratar sobre o avanço obtido após o advento da Constituição de 1988 no tocante à normativa que estabeleceu, no ano de 2003, por meio da Lei n. ${ }^{\circ} 10.639$, as Diretrizes Curriculares Nacionais para a Educação das Relações Étnico-Raciais e para o Ensino de História e Cultura Afro-Brasileira e Africana. O estudioso afirma que tal mudança se deu em função da

\footnotetext{
[...] constatação entre pesquisadores e estudiosos de diversas áreas do conhecimento e como uma decorrência da ação política, denunciatória e reivindicativa dos movimentos sociais de que o teor da escrita da história pátria não foi elaborada na perspectiva dos colonizados, de suas contribuições no processo de formação cultural do País, nem a partir dos seus relatos, muito menos dos seus processos civilizatórios [...]. (NUNES NETO, 2016, p. 133).
}

Uma educação para além das amarras da colonialidade prescinde de um processo intrínseco, da promoção do autoconhecimento e retorno às origens histórico-culturais que, paradoxalmente, incutiram nos negros o lugar da subalternidade. Ser livre, nesta concepção, é ter preservadoe efetivado o direito à memória. Para romper com as amarras da subsunção cognitiva e, portanto, formativa do cidadão, fundamental é a constituição de práticas pedagógicas que promovam o acesso à história e cultura afrodescendente, a fim de que os sujeitos sejam capazes de perceber o seu lugar no mundo - essência da transformação social. 
A formação da identidade brasileira se deu com a integração de pluralidades culturais, tornando-a, nas palavras de Kabengele Munanga, uma "colcha de retalhos". $O$ autor considera que essa diversidade característica faz com que a chamada cultura nacional "não impeça a produção cultural das minorias étnicas, apesar da repressão que existiu no passado, mas apenas consiga inibir a expressão política dessas enquanto oposição dentro do contexto nacional" (MUNANGA, 2009, p. 452). Considerando, pois, que "a identidade é um processo sempre negociado e renegociado, de acordo com os critérios ideológico-políticos e as relações de poder" (MUNANGA, 2009, p. 453), preservar a memória afrodescendente é ir de encontro às estratégias de homogeneização histórico-cultural que aprofundam as disparidades sociais. 